\title{
Research on the Application of Cloud Computer Assisted Instruction
}

\author{
Lehui Huang ${ }^{a}$, Miaomiao $\mathrm{Li}^{\mathrm{b}}$ \\ Education School, Jiangxi Science \& Technology Normal University, Nanchang, China \\ aHLH8899@163.com, bLiMiaomiao0710@163.com
}

Keywords: cloud computing; cloud computing service platform; CCAI.

\begin{abstract}
With the development of cloud computing network, cloud computing assisted instruction (CCAI) has consequently drawn increasing attention. The application of cloud computing in education and teaching has injected fresh blood into our education field and has promoted the development of education informationization and the transformation of the concept. The paper expounds the concept of cloud computing and CCAI, the characteristics of CCAI, discusses the principle of the application of CCAI, and points out the issues that should be paid attention to in the application of CCAI.
\end{abstract}

\section{Introduction}

When Google puts forward the concept of cloud computing with the new and good network application mode, cloud computing obtains IT infrastructure using pattern of unlimited cloud resources and cloud services through the network according to the demand at any time, which also means the new direction of the internet. While the innovative technology puts forward development and application, cloud computing not only affects people's work and life style, but also absorbs the attention of the education field. The era of cloud computing is a new stage of education informationization development. It will exert profound influence on the construction of education resources and the change of teaching mode. In recent years, many problems exist in education and teaching, for example, the curriculum task is heavy, teachers' strength is weak, etc. the concept of CCAI and the characteristics of cloud computing determines that teaching environment based on cloud computing platform service will provide the effective methods and ways to solve the problems above. Therefore, it is necessary to carry out the actual research work on CCAI.

\section{The overview of cloud computing assisted instruction}

The meaning of cloud computing. Due to difference understanding perspectives, there are different description methods of cloud computing. Simply, cloud computing makes the information and resources together, letting the data processing completed by single computer change into by a large number of distributed computer, and the users can access to the internet to realize the computing and storage in the cloud.

The concept of cloud computing assisted instruction. When cloud computing enters into the education field, it has brought a new concept for us: cloud computing assisted instruction, referred to as CCAI. The so-called cloud computing assisted instruction refers to that, the school and teachers use the convenient service provided by cloud computing technology to build personalized and informatization teaching environment, so as to support teachers' teaching and students' learning courses and improve the teaching quality. At present, the application of cloud computing in education mainly has: school website, online learning system, teaching management system, network teaching resource website, interaction platform of school and parents, etc. these systems provide great convenience for the teaching work in creating teaching resources, designing teaching resources, organizing teaching activities, and implementing teaching evaluation.

The characteristics of CCAI. Except the basic characteristics of computer assisted teaching, CCAI has new characteristics of adapting to the requirements of education informationzation. Firstly, improve learning productivity. Cloud computing enhances the flexibility and agility of network 
learning, reduces the cost and difficulty of web learning resources and services, create flexible and agile learning way, create rich learning environment, thus help to improve the learning productivity and ultimately improve the learning effect. Secondly, collaborative sharing. Many users provide and share resources, avoiding that the limited resources cannot be fully utilized. Unlimited resources and unlimited service support remote collaborative learning and school collaborative learning. The E-learning service and data can be shared to the greatest extent, avoiding the repeated development of education information system and the waste of education resources. Thirdly, safe and reliable. Data in the cloud do not have to back up. Cloud storage services provided by cloud computing can provide protection and backup safety for important data, and students and teachers can easily access their important data whenever and wherever without worry about data loss or viruses. At the same time, cloud computing supports data sharing through strict permission management strategy. Fourthly, economic and efficient. The cloud service reduces huge cost of hardware and software in infrastructure resource construction. Service can change according to the elasticity of demand, and educational institutions only needs to pay for the use part. Through CCAI, you only need to configure the low energy consumption net book and connect with CCAI platform to satisfy the information teaching activities and adapt to the requirements of low carbon education in today's society.

\section{Application principles of CCAI}

People-oriented. Highlight the people-oriented, and center on the learners. Starting from the actual demand of learning participants, present real learning situation to the maximum, and layout and arrange authentic learning activity content. In the organization of resources, allocate the resources rationally, highlight the moderation of learning style and learning content, and create humane environment of teaching application.

Reasonable layout. In the precondition of ensuring the intellectual property rights, the reference resources in preschool preview, teaching process and school review should consider the set as much as possible. The design style of interface and forum should be unified to facilitate the browsing and learning of users; establish stable cyber source and ensure its efficiency; update resource database to ensure the learning resource novel, thus stimulating participants' learning interest.

Strengthen cooperation. Cooperation is the basis and premise of CCAI. In order to realize the optimization of teaching effect, it should pay attention to the collaborative design of the whole learning process. Taking CCAI environment created by Google collaboration platform for example, the interaction between teachers and students, cooperation and experience exchange between departments fully embodies the principle of collaborative sharing.

\section{Key problems in the application of CCAI}

Although facing a variety of problems in the application of CCAI, the key problems are mainly the following.

The presentation of teaching content should avoid material accumulation. In the construction of cloud computing learning environment, the teaching content is the main part. From the current cloud computing application, the presentation of teaching content also continue the old road of present-type teaching website, so data accumulation is common. The focus of cloud computing learning environment should be the teaching design. In the cloud computing platform, how to design the teaching and how to present the teaching module become the urgent problems to be solved in CCAI. We suggest that the teaching content should be present in a simple interface, the navigation relationship is clear, and course modules adapt to the actual teaching needs. The link of the first and second layer course module usually use the linear link, and the link of the second and third can consider cross link, thus avoiding the link relationship between the contents too complicated to produce artificial barrier to students' learning.

Improve the effectiveness and utilization of the learning resources. There are large amounts of information on the internet, and a huge amount of new information generate constantly every day, so 
screening mass information is an important method to test the validity of resources. In the age of computer aided instruction, the administrative agencies, schools and education enterprises establish a large number of education information resources. But in the age of cloud computing, we can change from the past resource library and material library to cloud service environment, so as to improve the utilization rate of resources and avoid the waste of resources, thus making the sharing of educational information resources more efficient and convenient.

Whether students' learning records in cloud computing platform truly reflects students' learning situation. Because CCAI is the teaching through cloud computing platform, teachers and students are usually separated by time and space. Whether the record of students' learning situation in the cloud computing platform can truly reflect the students' learning situation? Such a situation exists. While teachers are explaining teaching content through cloud service platform in another place, some students who are not in the eyes of teachers leave the computer to do other things after landing platform, some are busy doing other things although not leaving the computing, such as, playing games, chatting, browsing the webpage. Although the situation don't begin in the cloud service times, the function of cloud service platform has good interactivity, the users can try a variety of integrated service tool as far as possible to avoid the distraction of students.

Establish effective evaluation standard of student learning. In learning process, it is necessary to evaluate students' learning situation, and the evaluation basis is evaluation criteria and evaluation assessment made before. These evaluation criteria and evaluation gauge is designed from the angle of how teachers treat their students. Pointing at students' behavior in the cloud computing environment, we must establish appropriate evaluation criteria; for the interaction and collaborative learning situation between students, the establishers of learning environment should give reasonable and accurate evaluation. Whether the evaluation is effective depends on the reliability and validity of evaluation. In order to make students more willing to accept the assessment, we hold that, in the design of a variety of evaluation criteria and rubric, we should design the evaluation scale according to the features of cloud service learning environment. For example, research learning environment can take the research output as the final evaluation, the methods adopted in the research process and collective cooperation situation as process evaluation. In addition, the evaluation should combine with subject practice, and evaluation criteria of different professions should ensure significant difference in the premise of association degree.

Improve students' learning and quality by using cloud computing platform. Select the cloud computing platform suitable for students' learning to construct students' autonomous learning system and build autonomous learning environment, place the problem in the cloud computing platform students like, which can stimulate students' learning interest, enhance their information literacy, scientific literacy and scientific inquiry ability. Change the traditional classroom teaching process, and make full use of various cloud service tool to train the students' creative thinking and critical thinking.

\section{Conclusions}

Cloud computing is the social services provided by a large number of computer server group to users. As one of the most computing model manifesting the spirit of the internet, cloud computing will show great vitality and change our learning way. Schools and teachers should fully use the service provided by cloud computing to promote the teaching, and how to do this needs to further design its application in teaching on the basis of the study and give full play to its technology characteristic and superiority, thus reflecting and enhancing its value in the application of education.

\section{References}

[1]Zhongwen Xia. Critical thinking of cloud computing assisted instruction[J]. Chinese information technology education, 2010(11). 
[2] Yanling Shang. The application of cloud computing assisted instruction[J]. Journal of Anyang Normal University, 2012(5).

[3] Li Yu. The cloud computing assisted teaching application case "multimedia course making" course website[J]. Chinese education informatization, 2011(1).

[4]Yubin Fan. Discussion on computer assisted instruction based on cloud computing technology [J]. Computer CD software and application, 2014,17(2): 225-226.

[5]Yunjuan Bai, Shusheng Shen. Cloud learning: Learning concept stimulated by cloud computing[J]. Chinese audio-visual education, 2011(4).

[6]Chunlei Fan. Research on the assisted instruction based on cloud computing[J]. Computer programming skills and maintenance, 2014,(6):109-110.

[7] Lingqi Kong. Study on the impact of cloud computing on education[J]. Journal of Jiaozuo Normal Unversity, 2011(1). 